David R. Snydman, Section Editor

\title{
BK Virus: Opportunity Makes a Pathogen
}

\author{
Hans H. Hirsch \\ Transplantation Virology, Department of Clinical Biological Sciences, University of Basel, and Division of Infectious Diseases, University Hospital Basel, \\ Basel, Switzerland
}

More than $70 \%$ of the general population worldwide has serological evidence of exposure to Polyomavirus hominis type 1, better known as BK virus (BKV). BKV infection typically occurs during childhood, without specific symptoms, followed by a state of nonreplicative infection in various tissues, with the urogenital tract as the principal site. Asymptomatic reactivation and low-level replication with viruria is observed in 5\% of healthy individuals. Persistent high-level BKV replication is the hallmark of polyomavirus-associated nephropathy in renal transplantation and of hemorrhagic cystitis in bone marrow transplantation. Since these manifestations are rare in other types of immunocompromised patients, the presence of specific cofactors is postulated. The role of BKV in autoimmune disease and cancer is a controversial topic and is difficult to determine, because the pathology no longer depends on BKV replication. This article discusses current views of pathogenesis, diagnosis, and treatment

In the past decade, the human polyomavirus type 1, named "BK virus" (BKV) after the initials of the first affected patient, surfaced as a significant pathogen in kidney transplant recipients by causing polyomavirus-associated nephropathy (PVAN) $[1,2]$. Increasing prevalence rates of PVAN $(1 \%-10 \%)$ have been reported since then, with allograft dysfunction and loss in $>50 \%$ of cases $[3,4]$. Thus, PVAN is viewed as one of the leading causes of renal allograft loss in the first 2 years after transplantation. Although BKV was discovered as early as 1970, the pathologic significance of BKV in human diseases remained essentially confined to an association with late-onset hemorrhagic cystitis in bone marrow transplantation, the specificity of which has been questioned [4]. This clearly distinguished $\mathrm{BKV}$ from the other human polyomavirus type 2, JC virus (JCV), also named after the initials of the first patient. JCV was eagerly hunted for, after particles of typical polyomavirus morphology had been detected in 1965 by electron microscopy in brain lesions from patients with progressive multifocal leukoencephalopathy, a rare demyelinating disease first described in immunocompromised patients in 1958. However, new diagnostic tools - in particular, identification and quantification of BKV in plasma, proved useful in diagnosis and management

Received 25 March 2005; accepted 22 April 2005; electronically published 14 June 2005 Reprints or correspondence: Dr. Hans H. Hirsch, Transplantation Virology, Institute for Medical Microbiology, Petersplatz 10, CH-4003 Basel, Switzerland (hans.hirsch@unibas.ch).

Clinical Infectious Diseases 2005; 41:354-60

(C) 2005 by the Infectious Diseases Society of America. All rights reserved. $1058-4838 / 2005 / 4103-0014 \$ 15.00$ of PVAN $[5,6]$ and are now available to reevaluate the pathogenic role of BKV in other risk groups and diseases [7].

\section{EPIDEMIOLOGICAL ASPECTS}

The combined virological, epidemiological, and clinical data (i.e., the high prevalence of infection, low morbidity, asymptomatic reactivation, and host specificity) suggest coevolutionary adaptation of BKV and the human host [4]. Primary infection typically occurs during early childhood, after the waning of maternal antibodies. Before the age of 10 years, the seroprevalence increases to $50 \%$, and it reaches $>70 \%$ in adults [8]. JCV antibody prevalence shows a similar but slightly delayed pattern, indicating independent transmission despite considerable genetic homology of $70 \%$. Exposure to the polyomavirus of Rhesus macaques, SV40, resulted from contaminated poliovirus and adenovirus vaccines in the 1960s and may still be ongoing in zoos and animal parks [9], but widespread circulation among humans is not supported by serological data [8]. The natural route of BKV transmission has not been resolved and may be respiratory or oral. BKV, like JCV, is fairly resistant to environmental inactivation, and both have been detected in human sewage. A state of nonreplicative infection, termed "latency," is established in renal tubular epithelial and urothelial cells. Reactivation and low-level replication with asymptomatic viruria occurs in 5\% of healthy individuals [4]. The prevalence may increase with pregnancy, older age, or immune dysfunction, to rates of $>60 \%$. In addition, the level of replication may increase to a BKV DNA load from $<10^{5}$ to $>10^{7}$ copies $/ \mathrm{mL}$ of 
urine. However, BKV disease is rare, which suggests that additional factors are required.

\section{VIROLOGICAL ASPECTS}

BKV belongs to the genus Polyomavirus of the family Polyomaviridae, which is defined by a typical morphology of nonenveloped virions with icosahedral capsids with a $40-\mathrm{nm}$ diameter that enclose the small circular double-stranded DNA genome of $5 \mathrm{~kb}$. The genome architecture is conserved and consists of the noncoding control region that contains the origin of replication and bidirectional promoters, the early genes encoding the small tumor antigen and the large tumor antigen (LTag), and the late genes encoding the viral capsid proteins (VP1-VP3) and the agnoprotein. LTag is a conserved multifunctional regulator of polyomavirus transcription and replication. LTag interacts with host cell proteins, including the tumor-suppressor gene products $\mathrm{p} 53$ and retinoblastoma $\mathrm{pRb}$, and it subverts host cell division to recruit factors for viral DNA replication [10]. Unlike replication of herpesviruses, polyomavirus replication is largely dependent on host cell factors and, with the exception of LTag DNA helicase, does not encode typical antiviral drug targets, such as thymidine kinases or viral DNA polymerase. The close virus-host relationship is illustrated by polyomavirus genomes forming chimeric nucleosomes with host cell histones, which are packaged into viral particles. In replication-permissive cells, expression of the viral capsid proteins is followed by virion assembly in the nucleus, which eventually results in host cell lysis to release infectious progeny. Thus, BKV replication is cytopathic. The release of viral and cellular constituents elicits a nonspecific inflammatory reaction, followed by specific humoral and cellular immune responses in immunocompetent hosts [4].

\section{BKV DISEASE}

High prevalence, latent infection, and asymptomatic reactivation of BKV complicate the appreciation of its pathogenic role. Thus, for the purposes of the present study, the terms "BKV infection," "BKV replication," and "BKV disease" are defined in table 1.

Polyomavirus infections have been associated with diverse pathologies. In particular, the association of BKV with autoimmune disease and cancer is controversial, which reflects the difficulty of confirming histopathologic definitions of BKV disease; nevertheless, I present some hypotheses here (figure 1).

In autoimmune disease, polyomavirus replication is thought to trigger a pathologic immune response. In experimental studies, autoimmune responses could be induced by exposure to viral DNA-protein complexes involving histones or LTag [11], and an association between BKV and systemic lupus erythematodes has been proposed. The hypothetical role of BKV infection in autoimmune disease is not specific, and exposure to
Table 1. Terminology used in the present study of BK virus (BKV).

\begin{tabular}{ll}
\hline Term & \multicolumn{1}{c}{ Definition } \\
\hline BKV infection & $\begin{array}{c}\text { Case with serological or virological evidence of } \\
\text { virus exposure, including replicative and nonre- } \\
\text { plicative states }\end{array}$ \\
BKV replication & $\begin{array}{c}\text { Case with evidence of virus multiplication (active } \\
\text { or lytic infection) obtained by detection of infec- } \\
\text { tious virus, virions, structural proteins or their } \\
\text { mRNA, or cell-free DNA in nonlatency sites } \\
\text { (e.g., plasma or CSF); by cytological analysis } \\
\text { (of decoy cells); or by histological analysis } \\
\text { Case with histological evidence of BKV-mediated } \\
\text { organ pathology }\end{array}$ \\
\hline
\end{tabular}

other infectious and noninfectious antigens might elicit a similar response in a predisposed patient. It is likely that as-yet undefined (immuno)genetic determinants and/or circumstances of infection provide necessary cofactors [11].

In oncogenic disease, activation of host cell replication induced by viral proteins like LTag is uncoupled from viral lategene expression, virion assembly, and subsequent host cell lysis [10]. Hypothetically, uncoupling from viral late-gene expression might occur either genetically, by chromosomal integration, or functionally, by interference with concerted late-gene expression. Although cases of metastatic urothelial carcinoma [12], adenocarcinoma [13], and early-stage prostate neoplasia [14] have been discussed in support of experimentally demonstrated oncogenic potential of BKV, the diagnosis of the role of BKV infection as "driver," "innocent passenger," or transient "hit and run" agent is difficult to prove with the current diagnostic tools.

Given the high prevalence of BKV infection in the human population, it seems that a potential role, if any, of BKV autoimmune and oncogenic disease must require as-yet undefined genetic or acquired cofactors. It is important to emphasize, with regard to conceptual and diagnostic concerns, that the pathogenesis of both mechanisms no longer requires ongoing $\mathrm{BKV}$ replication. By contrast, high-level BKV replication is a hallmark of diseases such as PVAN and hemorrhagic cystitis and may serve as a noninvasive diagnostic marker for screening and monitoring.

\section{BKV-ASSOCIATED ORGAN MANIFESTATIONS}

Kidney. Kidney manifestations are not well defined in immunocompetent individuals, although latent polyomavirus infection presumably follows primary viremic seeding. Even in immunocompromised patients, BKV disease of autologous kidneys is restricted to rare cases. Nevertheless, one of the first reported cases of tubulo-interstitial nephritis (or PVAN pattern B) progressing to fibrosis and tubular atrophy (or PVAN pattern C) was observed in a child with hyper-IgM syndrome, most 


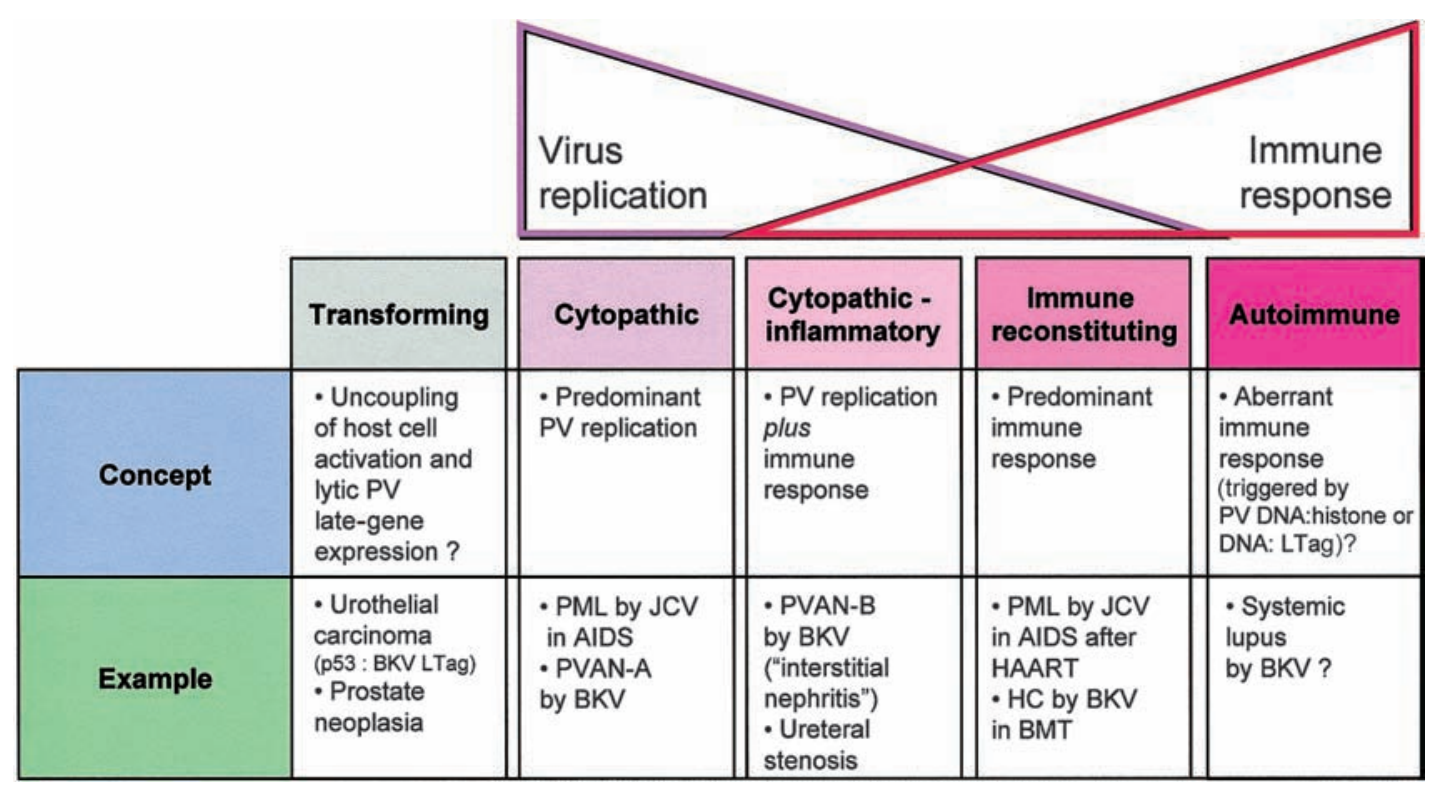

Figure 1. Patterns of polyomavirus (PV) pathology during virus replication and immune response. A colon (:) indicates interaction. BKV, BK virus; BMT, bone marrow transplantation; HC, hemorrhagic cystitis; JCV, JC virus; LTag, large T antigen; PML, progressive multifocal leukoencephalopathy; PVAN-A and PVAN-B, polyomavirus-associated nephropathy patterns $A$ and $B$, respectively.

likely after primary replication [15]. PVAN is rare in other transplantation procedures, including solitary pancreas [16], heart [17], lung [18], and hematopoietic stem cell [19] transplantations, despite the use of similar or more intense immunosuppression in the transplant recipients. The emergence of PVAN in renal transplantation represents a new challenge from an old companion and emphasizes the role of renal allograft-specific determinants and opportunities in the pathogenesis of PVAN.

The diagnosis of PVAN requires the histological demonstration of BKV replication and organ damage. Renal tubular epithelial cells typically show enlarged nuclei with amorphous, basophilic viral inclusions [20, 21]. Variant inclusions have also been described, and immunohistochemical staining for LTag is widely used as a confirmatory assay. Histological studies indicate that PVAN progresses through presentations that are initially predominantly cytopathic (pattern A), followed by a cytopathic-inflammatory stage without significant fibrosis (pattern $\mathrm{B}$ ) and a late stage with predominant tubular atrophy and fibrosis (pattern C). PVAN patterns B and C were significantly associated with allograft loss [22]. This provided independent evidence in support of the notion that early diagnosis of PVAN is associated with improved outcome after reduction of immunosuppression $[6,23,24]$.

The risk factors for PVAN in renal transplantation are controversial, which may be a reflection of methodological differences between the various studies. In addition, it seems likely that PVAN requires multiple synergizing factors that include characteristics of the patient (i.e., older age, male sex, white race, negative serostatus before transplantation, and diabetes), of the transplant (i.e., HLA-mismatches, prior acute rejections, ischemia, and calcineurin-inhibitor toxicity), and of the virus (i.e., serotype, genome mutations and rearrangements, immune evasion, and fitness) $[4,25]$. However, immunosuppression is generally accepted as the key modulator that increases the risk, relative to its potency, and that permits unchecked high-level replication [26]. Practically all cases of PVAN have been diagnosed in patients who were receiving triple combinations of drugs from 4 classes of immunosuppressive agents. The coincidence of PVAN with the widespread use of tacrolimus and mycophenolate mofetil (MMF) has caused much debate [27]. It has been pointed out elsewhere that neither drug is necessary for PVAN to occur, because PVAN has been observed in patients who were not receiving tacrolimus or MMF [2]. Reflecting the potency, however, BKV replication is significantly associated with combinations of tacrolimus and MMF, compared with other drug combinations [28].

There are 4 issues of particular interest with regard to antiviral immune control and transplantation.

1. Increasing HLA-mismatches, prior rejection episodes, and intensification of immunosuppression by antirejection treatment, including an increasing number of steroid pulses, were associated with BKV replication and disease in a prospective study [6] and in a case-control study [29] but were not found to be associated in other studies [30, 31].

2. BKV-seronegative transplant recipients, particularly those who are pediatric patients, are at increased risk for BKV 
replication and PVAN $[32,33]$, but seropositive recipients are not protected from BKV viremia or disease [6]. In patients with PVAN, BKV-specific T cells were not detectable in the peripheral blood, and, after reduction of immunosuppression, they (re)appeared in 2 patients after clearance of BKV viremia and resolution of PVAN [34]. These data suggest that BKV-specific $\mathrm{T}$ cell response might provide information that would complement the data on BKV load in plasma.

3. Cytomegalovirus (CMV) replication has been suggested to promote $\mathrm{BKV}$, either directly or indirectly [35]. However, no correlation was observed in a detailed study of CMV- and $\mathrm{BKV}$-seropositive patients who did not receive CMV prophylaxis [6]. Unlike CMV, BKV replication and disease were not associated with the use of antilymphocyte globulin when it was administered for induction but were associated when it was given as rejection treatment [6], which suggests differences between the 2 viruses in control and location of replication.

4. A critical cofactor of PVAN might be host cell regeneration after tubular epithelial cell injury from immunological, drug-related, mechanical, or ischemic assaults [2, 7, 36]. Replicating tubular epithelial cells in the presence of weakened immune functions might provide the fertile microenvironment for high-level BKV replication and organ involvement, whereas continuously proliferating cells of the urothelial layer readily support BKV replication without significant injury [2].

In clinical practice, it seems conceivable that patients receiving a renal allograft infected with BKV (donor positive, recipient negative) or organs with a high latent load might develop BKV replication in the absence of potent immunosuppression or antirejection treatment, whereas antirejection treatment might be required for BKV replication in transplant recipients with a sizeable $\mathrm{BKV}$ immune response. Given the heterogeneity of risk factors and patient characteristics, it is important to emphasize that stratification of the risk of PVAN can be done by screening for BKV replication in urine and plasma. Similar results were obtained in 3 prospective studies $[6,28,37]$ that reported BKV viruria in $30 \%, 35 \%$, and $28 \%$ of renal transplant recipients. In the 3 studies, BKV viremia was observed in $13 \%, 11.5 \%$, and $12.4 \%$ of patients and developed 4-7 weeks after BKV viruria $[6,28,37]$. Because the sensitivity and negative predictive value of BKV viruria for PVAN is close to $100 \%$, PVAN can be ruled out in $70 \%-90 \%$ of patients by use of urine cytology or PCR studies. On the other hand, if BKV viruria is detected, the risk of PVAN is increased, and adjunct studies are warranted; persistent BKV DNA viral loads of $>10,000$ copies/mL of plasma for $\geqslant 4$ weeks $[4,6,22]$ or BKV VP-1 mRNA loads of $>6.5 \times 10^{5}$ copies $/ n g$ of total RNA [38] were found to be $>93 \%$ specific and $93 \%$ sensitive for histologically documented PVAN. Screening for $\mathrm{BKV}$ replication in renal transplant recipients is therefore recommended (1) at least 3 times monthly for the first 2 years after transplantation, (2) when allograft dysfunction is noted, and (3) when allograft biopsies are performed for any reason, including for surveillance [26].

Although allograft biopsy is highly specific ("definitive" PVAN), it is important to realize that the sensitivity is limited because of focal involvement, particularly in the early stages, and because of presentation may be mistaken as acute rejection or chronic allograft nephropathy. In a careful study, Drachenberg et al. [22] observed at least 30\% discordant resultsthat is, both PVAN-positive and PVAN-negative findings-for biopsy cores obtained from patients with PVAN at the same visit. With a working terminology similar to that for invasive fungal disease, "possible" PVAN is defined as the presence of BKV viruria, "presumptive" PVAN is defined as a BKV viral load of $>10,000$ copies/mL of plasma or by a BKV VP-1 mRNA level of $>6.5 \times 10^{5}$ copies/ng of total urine RNA, and "definitive" PVAN is defined as histological evidence of allograft involvement [26]. For patients with "presumptive" PVAN, the risks and benefits of intervention have not been conclusively evaluated. However, recent data suggest that progression to PVAN can be safely prevented if BKV viremia is used as a guide to reduce immunosuppression [28].

The treatment of PVAN is difficult because of the absence of specific and well-tolerated antivirals. The current mainstay of intervention is to reduce the immunosuppressive maintenance therapy. Although no protocol has been formally tested, 3 strategies are currently used that consist of reducing, stopping, or switching components of the immunosuppressive regimen. Most centers reduce the calcineurin-inhibitor dosage (target trough levels for tacrolimus, $<6 \mathrm{ng} / \mathrm{mL}$; target for cyclosporine, $<150 \mu \mathrm{g} / \mathrm{mL}$ ) and stop or reduce MMF dosage to $<50 \%$ of the initial dosage. Switching from tacrolimus to cyclosporine (target, $<150 \mu \mathrm{g} / \mathrm{mL}$ ) or to sirolimus (target, $<6 \mathrm{ng} / \mathrm{mL}$ ) or switching from MMF to leflunomide has been successful in some cases $[6,39]$. Reduction of immunosuppression is controversial in cases with histological evidence of rejection that may benefit from a 2-step approach of initial steroid-pulse treatment followed by reduced immunosuppression [26]. Some of the patients may experience an immune reconstitution syndrome difficult to distinguish from rejection [4].

There is no established antiviral therapy for PVAN. Cidofovir and leflunomide have BKV-inhibitory activity in vitro, but the selectivity index appears to be moderate [40]. Replacing MMF with leflunomide has been successful, but the presumed antiviral activity is difficult to dissociate from reduced immunosuppression $[41,42]$. Cidofovir is transported into tubular epithelial cells, which explains its nephrotoxicity. BKV does not encode a viral DNA polymerase, which represents the primary target of cidofovir in CMV replication. Thus, anti-BKV activity of cidofovir has characteristics of chemotherapy, because it affects host cell replication to a significant extent [4]. In renal 
transplant recipients, off-label use of cidofovir has been proposed for PVAN at $1 / 10$ th or $1 / 20$ th of the dosage used to treat CMV retinitis $(0.25-0.33 \mathrm{mg} / \mathrm{kg})$, administered intravenously every 2 weeks, without probenicid. The success of such treatment was variable and was often coupled with reduced immunosuppression. Quinolone antibiotics have been shown to inhibit SV40 helicase activity in vitro, and the resolution of BKV replication was observed in a study of 10 renal transplant recipients [43]. Clearly, prospective, randomized studies are needed to better define the role of these agents.

Retransplantation after allograft loss due to PVAN has been successful in a limited number of patients, with recurrences in $2(15 \%)$ of 15 cases. In most of these patients, the same immunosuppressive drug regimens were reinstituted, but highlevel treatment was avoided [44]. Although graft nephrectomy may not be required in principle, a period without immunosuppression may be important for the reconstitution of BKVspecific immune effectors and the clearance of BKV viremia. This may not readily occur in patients who require continuous immunosuppression for another graft (e.g., pancreas); thus, renal allograft removal should be considered for patients with continuous viremia [45].

Ureter. Ureteral stenosis has been associated with BKV replication in renal transplant recipients. In some initial clinical studies and in animal models, histological evidence of BKV replication in ureteral stenosis was obtained $[4,46]$. This complication is now infrequently reported, which could be the result of decreased local damage due to better surgical techniques, the routine use of ureteral stents, and underdiagnosis of BKV, which occurs because surgical reconstruction and histological evaluations are less frequent and because the BKV etiology may be more difficult to prove in late pattern C-type fibrosed tissues [4]. A survey of 1629 consecutive renal transplantations between 1990 and 2001 identified ureteral stenosis in 52 cases (3.2\%). Delayed graft function, donor age, and CMV infection were significantly higher among these renal transplant recipients [47]. Data on the histological work-up were available for 25 cases, revealing thrombosis in 20 cases, ongoing CMV replication in 4 cases, and ongoing BKV replication in 2 cases. Whereas these data stress the overall importance of CMV, including its importance in vascular and ureteral complications, they point to a potentially underestimated role of BKV, which was also highlighted by 2 other case reports [48]. Of note, Brennan et al. [28] reported that the placement of ureteral stents was the sole independent parameter associated with sustained BKV viremia (hazard ratio, $4.3 ; P=.045$ ). It could be hypothesized that this procedure may cause sufficient local injury in the urothelial layer and may lead to BKV reactivation and spread into the circulation.

Bladder. Polyomavirus viruria (the presence of "decoy cells," or virions) may be associated with cystitis-like symptoms in $0.3 \%$ of immunocompetent individuals and only occasionally manifests as hemorrhagic cystitis. Hemorrhagic cystitis is also rare in HIV/AIDS and in solid-organ transplantation but represents a frequent complication in bone marrow transplantation (incidence, 5\%-60\%). Early-onset hemorrhagic cystitis has been linked to toxic effects of the conditioning procedure, whereas late-onset hemorrhagic cystitis, starting $>2$ weeks after transplantation, has been associated with BKV viruria [49]. However, approximately one-half of bone marrow transplant recipients with BKV viruria do not develop hemorrhagic cystitis. Although an association with higher BKV loads has been reported, the values are scattered and significantly overlap those found for patients without hemorrhagic cystitis. Moreover, other viral infections have been associated with hemorrhagic cystitis, such as adenovirus and CMV, which may even coexist. We have previously suggested that the pathogenesis of lateonset hemorrhagic cystitis corresponds to a sequence of events reminiscent of an immune-reconstitution syndrome [50, 51]. In this model, BKV provides an unspecific but highly prevalent antigen that becomes abundant because of high-level replication after conditioning and impaired immune surveillance. Reconstituted immune effectors engage with abundant BKV antigens and ignite an excessive inflammatory response. The damage and regeneration of urothelia and the antigen level act as contributing factors. Adenovirus and CMV can easily be accommodated in this model as contributing or substituting antigens. Recent data on significant BKV replication (BKV DNA load, $>10^{9}$ copies/mL of urine) and graft-versus-host disease before late-onset hemorrhagic cystitis are compatible with this model [52]. Urothelial damage and inflammation may also enhance the representation of BKV DNA in circulation, explaining the better positive-predictive value of BKV viremia, compared with BKV viruria [53], although these data require broader evaluation. The treatment of hemorrhagic cystitis is difficult, because no specific antivirals are available. Thus, the current mainstay is symptomatic treatment, with pain relief, bladder irrigation, and selective urological intervention. $\mathrm{Ci}$ dofovir has been used with success for patients with concurrent CMV infection, but there is a lack of systematic studies. It is possible that low-dose cidofovir might be a less toxic option. Recently, the antibiotic ciprofloxacin, a bacterial DNA gyrase inhibitor, was found at standard doses to reduce the increase in and the mean urinary level of BKV load in bone marrow transplant recipients [54]. The rate of hemorrhagic cystitis was not significantly reduced, but, because the sample size was small, larger multicenter studies are needed.

CNS. BKV was detected by PCR in the CSF of $3(1.5 \%)$ of 195 children with suspected encephalitis [55] and in $5(3.8 \%)$ of 131 adults with suspected viral meningitis and/or encephalitis that coexisted with signs of systemic illness [56]. In HIV/AIDS, $\mathrm{BKV}$ has been associated with 4 cases of meningoencephalitis 
that represented manifestations of disseminated BKV replication and disease, including retinitis, pneumonitis, and PVAN, as reviewed elsewhere [4]. Recently, BKV was the only agent detected in the CSF of a renal transplant recipient who had neurological deterioration and for whom findings of imaging studies suggested progressive multifocal leukoencephalopathy [57]. Clinical improvement and clearance of BKV viruria was observed after discontinuation of prednisone therapy and a switch from MMF to leflunomide. Thus, BKV replication in individuals with naive or immunosuppressed immune effectors might be associated with CNS manifestations, but further studies are needed.

Respiratory tract. BKV has been associated with flulike symptoms and upper respiratory tract infections in children, suggesting respiratory transmission [58]. BKV pneumonia with clinical signs and symptoms was documented in a child who underwent bone marrow transplantation [59]. No other pathogen except BKV was isolated from respiratory secretions before and after transplantation and from postmortem pneumonic lung tissue [59]. Also, BKV pneumonia was identified in autopsies of rare cases of severely immunocompromised patients with HIV-AIDS who showed disseminated BKV replication $[4,60]$.

\section{CONCLUSIONS}

BKV requires specific opportunities to unfold its diverse pathogenic potential. Profound immunosuppression that permits high-level BKV replication and organ pathology is the common hallmark of PVAN in renal transplantation and of hemorrhagic cystitis in bone marrow transplantation, although the pathogenesis for each likely differs. The association of BKV with autoimmune disease and cancer is controversial and requires the development of more-specific diagnostic tools, independent of testing for BKV replication.

\section{Acknowledgments}

I thank Drs. Cinthia Drachenberg and Emilio Ramos (Baltimore University of Maryland) and Juerg Steiger (University of Basel, Switzerland), for many enjoyable discussions.

Financial support. Swiss National Funds (grant 32-62021.00).

Potential conflicts of interest. H.H.H. has received research funding from Novartis Pharma AG (Basel, Switzerland) and Fujisawa GmBH (Munich, Germany).

\section{References}

1. Purighalla R, Shapiro R, McCauley J, Randhawa P. BK virus infection in a kidney allograft diagnosed by needle biopsy. Am J Kidney Dis $1995 ; 26: 671-3$.

2. Hirsch HH. Polyomavirus BK nephropathy: a (re-)emerging complication in renal transplantation. Am J Transplant 2002;2:25-30.

3. Ramos E, Drachenberg CB, Portocarrero M, et al. BK virus nephropathy diagnosis and treatment: experience at the University of Maryland Renal Transplant Program. Clin Transpl 2002: 143-53.
4. Hirsch HH, Steiger J. Polyomavirus BK. Lancet Infect Dis 2003;3: 611-23.

5. Nickeleit V, Klimkait $\mathrm{T}$, Binet IF, et al. Testing for polyomavirus type BK DNA in plasma to identify renal-allograft recipients with viral nephropathy. N Engl J Med 2000;342:1309-15.

6. Hirsch HH, Knowles W, Dickenmann M, et al. Prospective study of polyomavirus type $\mathrm{BK}$ replication and nephropathy in renal-transplant recipients. N Engl J Med 2002; 347:488-96.

7. Fishman JA. BK virus nephropathy-polyomavirus adding insult to injury. N Engl J Med 2002;347:527-30.

8. Knowles WA, Pipkin P, Andrews N, et al. Population-based study of antibody to the human polyomaviruses BKV and JCV and the simian polyomavirus SV40. J Med Virol 2003; 71:115-23.

9. Engels EA, Switzer WM, Heneine W, Viscidi RP. Serologic evidence for exposure to simian virus 40 in North American zoo workers. J Infect Dis 2004; 190:2065-9.

10. White MK, Khalili K. Polyomaviruses and human cancer: molecular mechanisms underlying patterns of tumorigenesis. Virology 2004; 324: $1-16$.

11. Van Ghelue M, Moens U, Bendiksen S, Rekvig OP. Autoimmunity to nucleosomes related to viral infection: a focus on hapten-carrier complex formation. J Autoimmun 2003; 20:171-82.

12. Geetha D, Tong BC, Racusen L, Markowitz JS, Westra WH. Bladder carcinoma in a transplant recipient: evidence to implicate the $\mathrm{BK}$ human polyomavirus as a causal transforming agent. Transplantation 2002; 73:1933-6.

13. Kausman JY, Somers GR, Francis DM, Jones CL. Association of renal adenocarcinoma and BK virus nephropathy post transplantation. Pediatr Nephrol 2004; 19:459-62.

14. Das D, Shah RB, Imperiale MJ. Detection and expression of human BK virus sequences in neoplastic prostate tissues. Oncogene 2004; 23 : 7031-46.

15. Rosen S, Harmon W, Krensky AM, et al. Tubulo-interstitial nephritis associated with polyomavirus (BK type) infection. $\mathrm{N}$ Engl J Med 1983; 308:1192-6.

16. Haririan A, Ramos ER, Drachenberg CB, Weir MR, Klassen DK. Polyomavirus nephropathy in native kidneys of a solitary pancreas transplant recipient. Transplantation 2002;73:1350-3.

17. Menahem SA, McDougall KM, Thomson NM, Dowling JP. Native kidney BK nephropathy post cardiac transplantation. Transplantation 2005; 79:259-60.

18. Milstone A, Vilchez RA, Geiger X, Fogo AB, Butel JS, Dummer S. Polyomavirus simian virus 40 infection associated with nephropathy in a lung-transplant recipient. Transplantation 2004; 77:1019-24.

19. Limaye AP, Smith KD, Cook L, et al. Polyomavirus nephropathy in native kidneys of non-renal transplant recipients. Am J Transplant 2005; 5:614-20.

20. Nickeleit V, Hirsch HH, Binet IF, et al. Polyomavirus infection of renal allograft recipients: from latent infection to manifest disease. J Am Soc Nephrol 1999; 10:1080-9.

21. Randhawa PS, Finkelstein S, Scantlebury V, et al. Human polyoma virus-associated interstitial nephritis in the allograft kidney. Transplantation 1999; 67:103-9.

22. Drachenberg CB, Papadimitriou JC, Hirsch HH, et al. Histological patterns of polyomavirus nephropathy: correlation with graft outcome and viral load. Am J Transplant 2004; 4:2082-92.

23. Buehrig CK, Lager DJ, Stegall MD, et al. Influence of surveillance renal allograft biopsy on diagnosis and prognosis of polyomavirus-associated nephropathy. Kidney Int 2003; 64:665-73.

24. Drachenberg CB, Papadimitriou JC, Wali R, et al. Improved outcome of polyoma virus allograft nephropathy with early biopsy. Transplant Proc 2004; 36:758-9.

25. Hirsch HH, Drachenberg CB, Steiger J, Ramos E. Polyomavirus-associated nephropathy in renal transplantation: critical issues of screening and management. In: Ahsan N, ed. Polyomavirus and human diseases. Georgetown, TX: Landes Biosciences, 2005.

26. Hirsch HH, Brennan DC, Drachenberg CB, et al. Polyomavirus-as- 
sociated nephropathy in renal transplantation: interdisciplinary analysis and recommendations. Transplantation 2005; 79:1277-86.

27. Hodur DM, Mandelbrot D. Immunosuppression and BKV nephropathy. N Engl J Med 2002;347:2079-80.

28. Brennan DC, Agha I, Bohl DL, et al. Incidence of BK with tacrolimus versus cyclosporine and impact of preemptive immunosuppression reduction. Am J Transplant 2005; 5:582-94.

29. Awadalla Y, Randhawa P, Ruppert K, Zeevi A, Duquesnoy RJ. HLA mismatching increases the risk of BK virus nephropathy in renal transplant recipients. Am J Transplant 2004; 4:1691-6.

30. Ramos E, Drachenberg CB, Papadimitriou JC, et al. Clinical course of polyoma virus nephropathy in 67 renal transplant patients. J Am Soc Nephrol 2002; 13:2145-51.

31. Rocha PN, Plumb TJ, Miller SE, Howell DN, Smith SR. Risk factors for BK polyomavirus nephritis in renal allograft recipients. Clin Transplant 2004; 18:456-62.

32. Ginevri F, De Santis R, Comoli P, et al. Polyomavirus BK infection in pediatric kidney-allograft recipients: a single-center analysis of incidence, risk factors, and novel therapeutic approaches. Transplantation 2003; 75:1266-70.

33. Smith JM, McDonald RA, Finn LS, Healey PJ, Davis CL, Limaye AP. Polyomavirus nephropathy in pediatric kidney transplant recipients. Am J Transplant 2004; 4:2109-17.

34. Comoli P, Azzi A, Maccario R, et al. Polyomavirus BK-specific immunity after kidney transplantation. Transplantation 2004; 78:1229-32.

35. Barri YM, Ahmad I, Ketel BL, et al. Polyoma viral infection in renal transplantation: the role of immunosuppressive therapy. Clin Transplant 2001; 15:240-6.

36. Atencio IA, Shadan FF, Zhou XJ, Vaziri ND, Villarreal LP. Adult mouse kidneys become permissive to acute polyomavirus infection and reactivate persistent infections in response to cellular damage and regeneration. J Virol 1993; 67:1424-32.

37. Hirsch HH, Tuncer M, Friman S, et al. Prospective study of polyomavirus BK viruria and viremia in de novo renal transplantation [abstract 457]. Am J Transplant 2005; 5:S272.

38. Ding R, Medeiros M, Dadhania D, et al. Noninvasive diagnosis of BK virus nephritis by measurement of messenger RNA for BK virus VP1 in urine. Transplantation 2002; 74:987-94.

39. Wali RK, Drachenberg C, Hirsch HH, et al. BK virus-associated nephropathy in renal allograft recipients: rescue therapy by sirolimusbased immunosuppression. Transplantation 2004; 78:1069-73.

40. Farasati NA, Shapiro R, Vats A, Randhawa P. Effect of leflunomide and cidofovir on replication of BK virus in an in vitro culture system. Transplantation 2005; 79:116-8.

41. Josephson M, Javaid B, Robert H, et al. Polyoma nephropathy: leflunomide blood levels needed for control of this infection [abstract 1563] Am J Transplant 2004; 4:S587.

42. Williams JW, Javaid B, Kadambi PV, et al. Leflunomide for polyomavirus type BK nephropathy. N Engl J Med 2005;352:1157-8.

43. Chandraker A, Ali S, Drachenberg C, et al. Use of fluorochinolones to treat BK infection in renal transplant recipients [abstract 1564]. Am J Transplant 2004; 4:S587.

44. Ramos E, Vincenti F, Lu WX, et al. Retransplantation in patients with graft loss caused by polyoma virus nephropathy. Transplantation 2004; 77:131-3.

45. Lipshutz GS, Mahanty H, Feng S, et al. BKV in simultaneous pancreaskidney transplant recipients: a leading cause of renal graft loss in first 2 years post-transplant. Am J Transplant 2005; 5:366-73.

46. van Gorder MA, Della PP, Henson JW, Sachs DH, Cosimi AB, Colvin RB. Cynomolgus polyoma virus infection: a new member of the polyoma virus family causes interstitial nephritis, ureteritis, and enteritis in immunosuppressed cynomolgus monkeys. Am J Pathol 1999; 154: 1273-84.

47. Karam G, Maillet F, Parant S, Soulillou JP, Giral-Classe M. Ureteral necrosis after kidney transplantation: risk factors and impact on graft and patient survival. Transplantation 2004; 78:725-9.

48. Fusaro F, Murer L, Busolo F, Rigamonti W, Zanon GF, Zacchello G. CMV and BKV ureteritis: which prognosis for the renal graft? J Nephrol 2003; 16:591-4.

49. Arthur RR, Shah KV, Baust SJ, Santos GW, Saral R. Association of BK viruria with hemorrhagic cystitis in recipients of bone marrow transplants. N Engl J Med 1986;315:230-4.

50. Binet I, Nickeleit V, Hirsch HH. Polyomavirus infections in transplant recipients. Curr Opin Org Transplant 2000; 5:210-6.

51. Hirsch HH, Kaufmann G, Sendi P, Battegay M. Immune reconstitution in HIV-infected patients. Clin Infect Dis 2004; 38:1159-66.

52. Bogdanovic G, Priftakis P, Giraud G, et al. Association between a high $B K$ virus load in urine samples of patients with graft-versus-host disease and development of hemorrhagic cystitis after hematopoietic stem cell transplantation. J Clin Microbiol 2004; 42:5394-6.

53. Erard V, Storer B, Corey L, et al. BK virus infection in hematopoietic stem cell transplant recipients: frequency, risk factors, and association with postengraftment hemorrhagic cystitis. Clin Infect Dis 2004; 39: 1861-5.

54. Leung AY, Chan MT, Yuen KY, et al. Ciprofloxacin decreased polyoma BK virus load in patients who underwent allogeneic hematopoietic stem cell transplantation. Clin Infect Dis 2005; 40:528-37.

55. Behzad-Behbahani A, Klapper PE, Vallely PJ, Cleator GM. BK virus DNA in CSF of immunocompetent and immunocompromised patients. Arch Dis Child 2003; 88:174-5.

56. Behzad-Behbahani A, Klapper PE, Vallely PJ, Cleator GM, Bonington A. BKV-DNA and JCV-DNA in CSF of patients with suspected meningitis or encephalitis. Infection 2003;31:374-8.

57. Hix JK, Braun WE, Isada CM. Delirium in a renal transplant recipient associated with BK virus in the cerebrospinal fluid. Transplantation 2004; 78:1407-8.

58. Goudsmit J, Wertheim-van Dillen P, van Strien A, van der NJ. The role of BK virus in acute respiratory tract disease and the presence of BKV DNA in tonsils. J Med Virol 1982; 10:91-9.

59. Sandler ES, Aquino VM, Goss-Shohet E, Hinrichs S, Krisher K. BK papova virus pneumonia following hematopoietic stem cell transplantation. Bone Marrow Transplant 1997; 20:163-5.

60. Vallbracht A, Lohler J, Gossmann J, et al. Disseminated BK type polyomavirus infection in an AIDS patient associated with central nervous system disease. Am J Pathol 1993; 143:29-39. 